\title{
Preparation and performance comparison of cellulose-based activated carbon fibres
}

\author{
Kanza Hina $\cdot$ Hantao Zou $\cdot$ Wu Qian · Danying Zuo $\cdot$ Changhai Yi
}

Received: 2 March 2017 / Accepted: 11 October 2017/Published online: 16 November 2017

(C) Springer Science+Business Media B.V., part of Springer Nature 2017

\begin{abstract}
Activated carbon fiber (ACF) is widely used sorbent material for wastewater treatment. Three natural cellulosic fibres (kapok, cotton, and ramie) and three regenerated cellulosic fibres (bamboo fiber, viscose, and lyocell) are used to prepare ACFs using chemical activation. These ACFs are characterized using scanning electron microscope, $\mathrm{X}$-ray diffraction (XRD), Fourier transform infrared spectroscopy (FTIR) testing, elemental analysis, adsorption property and nitrogen adsorption-desorption. XRD and FTIR spectrum of all six cellulosic ACFs are almost similar showing that ACFs have almost same chemical and physical composition. All cellulosic ACFs are constituted of $\mathrm{C}, \mathrm{H}$, ash and $\mathrm{O}$, but $\mathrm{C}$ content is higher in natural cellulosic fibres. Surface morphology and surface area of cellulosic ACFs play the basic role in adsorption. The 2 nd order pseudo kinetic model is fitted for all cellulosic ACFs as $\mathrm{R}^{2}>0.99$ and adsorption controlling process is chemical sorption. The adsorption capacity of the kapok-based ACFs is best, owing to their hollow structure, the micropores on surface and high specific surface area. Bamboo, ramie and cotton based ACFs also have high adsorption but they need more time to adsorb impurities than
\end{abstract}

K. Hina · H. Zou $(\bowtie) \cdot$ W. Qian · D. Zuo · C. Yi Key Laboratory of Green Processing and Functional Textile of New Textile Materials (Wuhan Textile University), Ministry of Education,

Wuhan 430073, Hubei, People's Republic of China e-mail: hantao.zou@wtu.edu.cn kapok based ACFs. Viscose based ACFs shows moderate adsorption, while the least adsorption is shown by the lyocell based ACFs because of their smooth and uniform structure. Adsorption analysis and other properties evaluation show that kapok fiber is the best precursor than other five cellulosic fibres.

Keywords Cellulose-based ACFs - Chemical activation - Adsorption - Absorption kinetics - Specific surface area

\section{Introduction}

Toxic waste water is becoming acute problem to the ecological system due to expansion in the industrialization and with the awareness; steps are taken to remove toxic elements from waste water before its discharge (Vargas et al. 2011; Shrestha et al. 2013; Gupta and Suhas 2009; Dastgheib et al. 2004; Du et al. 2013). Thus, there is increase in need of the mediums that is cheapest and efficient to eliminate the pollutant before the discharge of waste water. Many kinds of the procedure used and one of the best is adsorption using AC (Activated Carbon) (Dąbrowski et al. 2005; Singh et al. 2003; Suhas et al. 2007). AC possess many surface functional groups that have affinity for many adsorbates, justifying the extreme application of them for the treatment of the industrial effluent. They have large surface area and high porosity. It has also 
advantageous as it can be produced industrially at large scale. There are four forms in which activated carbon fibres are present i.e. powdered activated carbon, granular activated carbon, activated carbon pellet and activated carbon fiber. Among these four forms of AC activated carbon fibres (ACFs) have the advantage that they are produced in fibrous form from the fibres; make it easier to form entanglement with each other producing web and no need of the post treatments (AlcaAiz-Monge et al. 2002; Pelekani and Snoeyink 1999; Naindi et al. 2012; Maciá-Agulló et al. 2004; Subramanian et al. 2007; Zhang et al. 2010). Commercially available ACFs are derived from materials such as palm tree cobs, jute, flax, banana fiber, rice husk, coconut, hemp, vetiver roots, piassava fibres, PAN fibres, pitch base precursor, biomass, and agricultural waste etc. (El Qada et al. 2006; Williams and Reed 2006; Phan et al. 2006; Rosas et al. 2009; Aber et al. 2009). As the production cost is high from the synthetic precursor and the demand of the activated carbon fibres increases then there is need to look for the efficient natural resource especially wastes to make activated carbon fibres (Williams and Reed 2006; Rosas et al. 2009).

Activated carbon fibres can be produced using physical activation or chemical activation. The physical activation method comprises of the carbonization of the precursor at $600-900{ }^{\circ} \mathrm{C}$ in an inert environment to produce char that is afterward activated using $\mathrm{CO}_{2}$ and steam as oxidizing gases at $600-1200{ }^{\circ} \mathrm{C}$. Whereas, precursor is impregnated with the oxidizing chemical such as $\mathrm{ZnCl}_{2}, \mathrm{~K}_{2} \mathrm{CO}_{3}, \mathrm{AlCl}_{3}, \mathrm{Na}_{2} \mathrm{HPO}_{4}$, and $\mathrm{H}_{3} \mathrm{PO}_{4}$ in Chemical activation method and then heating is done in inert system such as argon or nitrogen gases in chemical activation (Aber et al. 2009). Comparison of physical and chemical activation is done by many researchers such as MaciáAgulló et al. (2004), Zhang et al. (2010), Williams and Reed (2006), Phan et al. (2006) and Altenor et al. (2009) and concluded that chemical activation give higher surface area. Chemically activated carbon has more tendency for adsorption and pores are mainly micro pores whereas, physically activated carbon has mainy mesopores.

Shrestha et al. (2013) studies the adsorption of $\mathrm{Zn}$ by activated carbon fibres made up of lignite and coconut shell. It reveals that ACFs are also very good adsorption medium for metals ions and with initial adsorbate concentration, removal percentage of $\mathrm{Zn}$ (II) decreased and Zn (II) equilibrium uptake increased. The maximum saturated monolayer adsorption is $9.43 \mathrm{mg} / \mathrm{g}$ and optimal contact time is $50 \mathrm{~min}$ because $\mathrm{Zn}$ ion concentration in solution decreases with temperature. Altenor et al. (2009) adsorb optimal amount of methylene blue by vetiver roots base activated carbon prepared by physical activation by steam and chemically activation by phosphoric acid having different impregnation ratios. Activated carbon has both micropores and mesopores, high surface area $\left(>1000 \mathrm{~m}^{2} / \mathrm{g}\right)$, and high pore volume i.e. up to $1.19 \mathrm{~cm}^{3} / \mathrm{g}$. Mesopores and acidic groups in activated carbon fibres help and favor the adsorption of methylene blue because of the electrostatic attraction between methylene blue and acidic functional groups such as carboxylic. Kumagai et al. (2010) compared the ultra-micropore volumes of commercially available activated carbon (CAC) and granular coconut shell based activated carbon (GCSAC). The adsorption of dibenzothiophene (DBT) is higher in GCSAC than $\mathrm{CAC}$ at lower equilibrium concertation (i.e. $<2$ ppm) because at the low equilibrium concentration produce a low concentration gradient in the pores, which might cause the surface functional groups to inhibit the transportation of DBT into the ultramicropores, thus resulting in reduced DBT uptake for ACF at $<2$ ppm. Mochida et al. (2000) states that pitch based activated carbon fibres are best for removal of $\mathrm{SO}_{\mathrm{x}}$ as compare to other precursor based activated carbon fibres and adsorption depends upon the heat-treatment temperature and surface area. ACFs produce by heat treatment at $900{ }^{\circ} \mathrm{C}$ and have $2150 \mathrm{~m}^{2} / \mathrm{g}$ surface area gives $100 \% \mathrm{SO}_{\mathrm{x}}$ adsorption at room temperature.

There are many literature studies on cellulosic based ACF individually but the comparison of different cellulosic based ACF on same parameters is very rare. Thus in this paper used six cellulosic kapok, viscose, ramie, cotton, bamboo, tencel to make activated carbon fibres using chemical activation approach. These produce fibres are characterised using SEM, FTIR analysis, and XRD. For the surface chemistry analyzation the pore size and specific surface area were also determined. The main focus of the study is on the comparison of adsorption kinetics of the activated carbon using methylene blue dye.

Surface area and adsorption of Cotton, Kapok, Ramie, Bamboo, Rayon and lyocell based ACFs are 
also compared with different materials in literature as given in Table 1.

\section{Experimental}

\section{Materials}

Six cellulosic fibres including cellulosic kapok, cotton, ramie, bamboo, viscose, lyocell (Tencel) were obtained from simple market in Wuhan, Hubei province, China. The commercial bamboo fibres with a diameter of about $11 \mathrm{um}$ are the cellulose fibres extracted and fabricated from natural bamboo. The hydrogen phosphate ammonia is obtained from the Xilong Chemical Company Limited in China. Methylene blue (MB), an analytical grade cationic dye purchased from Sinopharm Chemical Reagent China was chosen as the targeted adsorbate, without further purification prior to use. All reagents were analyticalgrade chemicals. Deionized water supplied by USF ELGA water treatment system was used to prepare all the reagents and solutions.

\section{Preparation of cellulosic ACFs}

The cellulose fibres were washed with $2 \mathrm{wt} \% \mathrm{NaOH}$ to eliminate some wax, ash and other small molecules. And then the fibres were be processed by two-step pretreatment, i.e., the cellulose fibres were first chemical activated and then oxidized. Chemical activation is selected as various studies showed that chemical activation give more surface area than physical activation (Maciá-Agulló et al. 2004; Zhang et al.

Table 1 Comparison of six cellulosic (Kapok, Ramie, Cotton, Bamboo, Rayon, and Tencel) ACFs with other prepared ACFs in literature

\begin{tabular}{|c|c|c|c|c|c|c|c|}
\hline Material & Activation & $\begin{array}{l}\mathrm{S}_{\mathrm{BET}} \\
\left(\mathrm{m}^{2} / \mathrm{g}\right)\end{array}$ & Adsorbate & $\begin{array}{l}\mathrm{Q}_{\mathrm{m}} \\
(\mathrm{mg} / \mathrm{g})\end{array}$ & $\begin{array}{l}\text { Concentration } \\
\text { rate }\end{array}$ & $\begin{array}{l}\text { Percentage } \\
\text { adsorption }\end{array}$ & $\begin{array}{l}\text { Saturation } \\
\text { time }\end{array}$ \\
\hline $\begin{array}{l}\text { Flamboyant pods (Vargas } \\
\text { et al. 2011) }\end{array}$ & $\mathrm{NaOH}$ & 2854 & MB & $874-890$ & $0.1-1 \mathrm{~g} / \mathrm{L}$ & - & $25 \mathrm{~min}$ \\
\hline Jute fiber (Phan et al. 2006) & $\mathrm{H}_{3} \mathrm{PO}_{4}$ & 959 & $\mathrm{AR}_{27}$ & 181.81 & $5-100 \mathrm{mg} / \mathrm{L}$ & - & - \\
\hline Jute fiber (Phan et al. 2006) & $\mathrm{CO}_{2}$ & 912 & $\mathrm{AR}_{27}$ & 151.50 & $5-100 \mathrm{mg} / \mathrm{L}$ & - & - \\
\hline $\begin{array}{l}\text { Coconut fiber (Phan et al. } \\
\text { 2006) }\end{array}$ & $\mathrm{H}_{3} \mathrm{PO}_{4}$ & 1303 & $\mathrm{AR}_{27}$ & 113.63 & $5-100 \mathrm{mg} / \mathrm{L}$ & - & - \\
\hline $\begin{array}{l}\text { Coconut fiber (Phan et al. } \\
\text { 2006) }\end{array}$ & $\mathrm{CO}_{2}$ & 1088 & $\mathrm{AR}_{27}$ & 74.63 & $5-100 \mathrm{mg} / \mathrm{L}$ & - & - \\
\hline $\begin{array}{l}\text { Vetiver roots (Altenor et al. } \\
\text { 2009) }\end{array}$ & $\mathrm{H}_{3} \mathrm{PO}_{4}$ & 1170 & MB & 144 & $50-300 \mathrm{mg} / \mathrm{L}$ & - & - \\
\hline $\begin{array}{l}\text { Rattan sawdust (Hameed } \\
\text { et al. 2007a) }\end{array}$ & $\begin{array}{l}\mathrm{KOH} \text { and } \\
\mathrm{CO}_{2}\end{array}$ & 1083 & MB & 294.12 & $100-500 \mathrm{mg} / \mathrm{L}$ & - & $3.5 \mathrm{~h}$ \\
\hline $\begin{array}{l}\text { Newspaper (Okada et al. } \\
\text { 2003) }\end{array}$ & $\mathrm{K}_{2} \mathrm{CO}_{3}$ & 1260 & MB & 340 & $1.2 \mathrm{~g} / \mathrm{L}$ & - & - \\
\hline $\begin{array}{l}\text { Newspaper (Okada et al. } \\
\text { 2003) }\end{array}$ & Steam & 1090 & MB & 190 & $1.2 \mathrm{~g} / \mathrm{L}$ & - & - \\
\hline $\begin{array}{l}\text { Piassava fiber (Avelar et al. } \\
\text { 2009) }\end{array}$ & $\mathrm{ZnCl}_{2}$ & 1190 & MB & 276.4 & - & - & - \\
\hline $\begin{array}{l}\text { Piassava fiber (Avelar et al. } \\
\text { 2009) }\end{array}$ & Steam & 658 & MB & 176.46 & - & - & - \\
\hline Kapok & $\left(\mathrm{NH}_{4}\right)_{2} \mathrm{HPO}_{4}$ & 1510.0 & MB & - & $20 \mathrm{mg} / \mathrm{L}$ & 86 & $2 \min$ \\
\hline Bamboo & $\left(\mathrm{NH}_{4}\right)_{2} \mathrm{HPO}_{4}$ & 1455.6 & MB & - & $20 \mathrm{mg} / \mathrm{L}$ & 85 & $6 \mathrm{~min}$ \\
\hline Ramie & $\left(\mathrm{NH}_{4}\right)_{2} \mathrm{HPO}_{4}$ & 1286.4 & MB & - & $20 \mathrm{mg} / \mathrm{L}$ & 85 & $15 \mathrm{~min}$ \\
\hline Cotton & $\left(\mathrm{NH}_{4}\right)_{2} \mathrm{HPO}_{4}$ & 1020.0 & MB & - & $20 \mathrm{mg} / \mathrm{L}$ & 83 & $30 \mathrm{~min}$ \\
\hline Viscose & $\left(\mathrm{NH}_{4}\right)_{2} \mathrm{HPO}_{4}$ & 980.2 & MB & - & $20 \mathrm{mg} / \mathrm{L}$ & 66 & $80 \mathrm{~min}$ \\
\hline Tencel & $\left(\mathrm{NH}_{4}\right)_{2} \mathrm{HPO}_{4}$ & 590.6 & MB & - & $20 \mathrm{mg} / \mathrm{L}$ & 17 & $60 \mathrm{~min}$ \\
\hline
\end{tabular}


2010; Williams and Reed 2006; Phan et al. 2006; Aber et al. 2009). The activation treatment was performed by impregnating the cellulose fibres with $200 \mathrm{~g} / \mathrm{L}$ ammonium phosphate at the mass ratio of 1:10 (fiber: ammonium phosphate) for $24 \mathrm{~h}$. The pre-oxidation treatment was carried out with heating the activated fibres at $200{ }^{\circ} \mathrm{C}$ in air for $2 \mathrm{~h}$. The pretreated samples were heated from room temperature to $650{ }^{\circ} \mathrm{C}$ in the TL-1200 tube-type furnace with a heating rate of $5{ }^{\circ} \mathrm{C} /$ min under an $\mathrm{N}_{2}$ flow rate of $200 \mathrm{~cm}^{3} / \mathrm{min}$ as according to $\mathrm{Du}$ et al. (2013) $650{ }^{\circ} \mathrm{C}$ give highest carbon yield along with high surface area. Thereafter, the fibres were isothermally heated for $70 \mathrm{~min}$ and then cooled to room temperature. After carbonization, the ACFs were washed using $1 \mathrm{~mol} / \mathrm{L} \mathrm{HCl}$ solution to selectively leach the ash from the carbons and washed with hot distilled water until the $\mathrm{pH}$ of the filtrate was neutral, and then dried in vacuum at $378 \mathrm{~K}$ overnight. The samples are referred to as kapok-based ACF, cotton-based ACF, ramie-based ACF, viscose-based ACF, bamboo-based ACF and tencel-based ACF, respectively.

\section{Characterization}

The chemical groups of the ACFs were examined using Fourier transform infrared (FTIR) spectrum analysis with a spectrometer (Tensor 27, Bruker Optics, Germany), in the scanning range of 4000-400 $\mathrm{cm}^{-1}$.

The X-ray diffraction (XRD) analysis was performed on the X'Pert Pro diffractometer (Panalytical)with $\mathrm{Cu} \mathrm{K} \alpha$ as the excitation radiation, operating at $40 \mathrm{kV}$ and $40 \mathrm{~mA}$ with the scanning frequency of $3\left(^{\circ}\right) /$ min in $2 \theta$ range of $5^{\circ}-90^{\circ}$.

Elemental analysis was carried out at $240{ }^{\circ} \mathrm{C}$ on an elemental analyzer (United States Perkin-Eimer Company) to determine the amount of carbon, hydrogen, oxygen and nitrogen in the ACFs. A portion of ACFs, about $10 \mathrm{mg}$, was placed in a tin foil and burnt completely in a vertical combustion tube. The carbon (C), hydrogen $(\mathrm{H})$ and ash contents of the ACFs were determined directly using the thermal conductively detector. Oxygen $(\mathrm{O})$ content was then obtained by mass difference, assuming that the ACF consisted only of carbon, hydrogen, ash and oxygen.

Methylene blue (MB) is used to evaluate the absorption performance of the cellulose-based ACFs. The $100 \mathrm{mg} / \mathrm{l} \mathrm{MB}$ solution has been taken. $20 \mathrm{mg} /$
$1 \mathrm{MB}$ solution was diluted in $15 \mathrm{ml}$ distilled water and $0.1 \mathrm{mg}$ of activated carbon fiber was stirred in the solution at room temperate using magnetic heating stirrer. Took $10 \mathrm{ml}$ sample every time using colorimetric tubes and added $10 \mathrm{ml}$ distilled water. Then the final MB concentration was determined using a UVVis spectrophotometer (Shimadzu Co. Ltd.) by measuring the light absorbance at a wavelength of $665 \mathrm{~nm}$.

The morphology micrographs of the fibres were measured by scanning electron microscopy (SEM) using a FEI Quanta 200 scanning electron microscope (FEI Company, Eindhoven, Netherlands). Before observation, the samples were coated with a thin layer by spraying gold metal using Ion Sputter (E-1010, Hitachi Co. Ltd., Chiyoda, Tokyo, Japan).

The textural parameters of the ACFs were determined using $\mathrm{N}_{2}$ adsorption desorption isotherms at $77 \mathrm{~K}$ (NOVA-1000, Quantachrome Instruments, USA). In preparation, the ACFs were degassed at $300{ }^{\circ} \mathrm{C}$ for $3 \mathrm{~h}$. The specific surface area $\left(\mathrm{S}_{\mathrm{BET}}\right)$ was calculated by the Brunauer-Emmett-Teller (BET) method using $\mathrm{N}_{2}$ adsorption isotherm data. The total pore volume $\left(\mathrm{V}_{\text {tot }}\right)$ was evaluated by converting the amount of $\mathrm{N}_{2}$ adsorbed at a relative pressure of 0.995 to the volume of liquid adsorbate. The micropore area $\left(\mathrm{S}_{\text {micro }}\right)$ and micropore volume $\left(\mathrm{V}_{\text {micro }}\right)$ were obtained by Dubinin-Radushkevich (DR) equation. The average pore size and the mesopore area $\left(S_{\text {meso }}\right)$ were calculated according to the Barrett-Joyner-Halenda (BJH) method.

\section{Results and discussion}

The activated carbon fibres prepared from six cellulose sources and these ACFs are stabilized during preoxidation. During carbonization carbon skeleton is formed due to the elimination of non-carbon elements such as $\mathrm{O}, \mathrm{H}$, and $\mathrm{N}$ from cellulose structure. At this stage the ACFs have rudimentary pore structure and pores size is enhanced by chemical activation of ACFs (Lee et al. 2009).

Figure 1 shows the FTIR spectra of the six kind of cellulosic ACFs. Obviously, the six cellulose-based ACFs have almost similar FTIR spectrum, suggesting similarity in their chemical structure. The FTIR spectra of the cellulose-based ACFs reveal a broad adsorption peak at $3433 \mathrm{~cm}^{-1}$, assigned to the stretching vibration of intra and intermolecular 
hydroxyl groups $(-\mathrm{OH})$. Bands for $\mathrm{C}-\mathrm{H}$ stretching vibration of methyl and methylene groups (2978 and $2831 \mathrm{~cm}^{-1}$ ) are negligibly small. The spectra shows a pronounced band at $1630 \mathrm{~cm}^{-1}$, that can be assigned to the $\mathrm{C}=\mathrm{C}$ stretching vibration in the structure of the activated carbon. The band at $1000-1300 \mathrm{~cm}^{-1}$ is usually found with oxidized carbons and has been assigned to $\mathrm{C}-\mathrm{O}$ stretching vibration in ester group. The adsorption peaks near $1119 \mathrm{~cm}^{-1}$, assigned to $\mathrm{C}-$ O stretching vibration, appear, indicating the existence of oxygen-containing functional groups within the ACFs. Nevertheless, it is also characteristic of phosphorus and phosphor-carbonaceous compounds present in $\mathrm{NaH}_{2} \mathrm{PO}_{4}$ activated carbons. The peak at $1163 \mathrm{~cm}^{-1}$ can be assigned to the $\mathrm{O}-\mathrm{C}$ stretching vibration in the $\mathrm{P}-\mathrm{O}-\mathrm{C}$ (aromatic) linkage. The band at $1080-1065 \mathrm{~cm}^{-1}$ could be due to $\mathrm{P}^{+}-\mathrm{O}^{-}$in acid phosphate esters and to the symmetrical vibration in polyphosphate chain $\mathrm{P}-\mathrm{O}-\mathrm{P}$ (Avelar et al. 2009). The peaks less than $1500 \mathrm{~cm}^{-1}$ for the three natural cellulose-based fibres (kapok, ramie and cotton) are slightly different to bamboo, viscose, and tencel-based ACFs. FTIR spectra for the three natural cellulosebased ACFs appear more peaks and higher intensities at less than $1500 \mathrm{~cm}^{-1}$, which may be attributed to more impurities and ash in the three natural cellulosic ACFs.

Figure 2 shows the XRD of the six cellulosic ACFs and all cellulose-based ACFs show similar diffraction

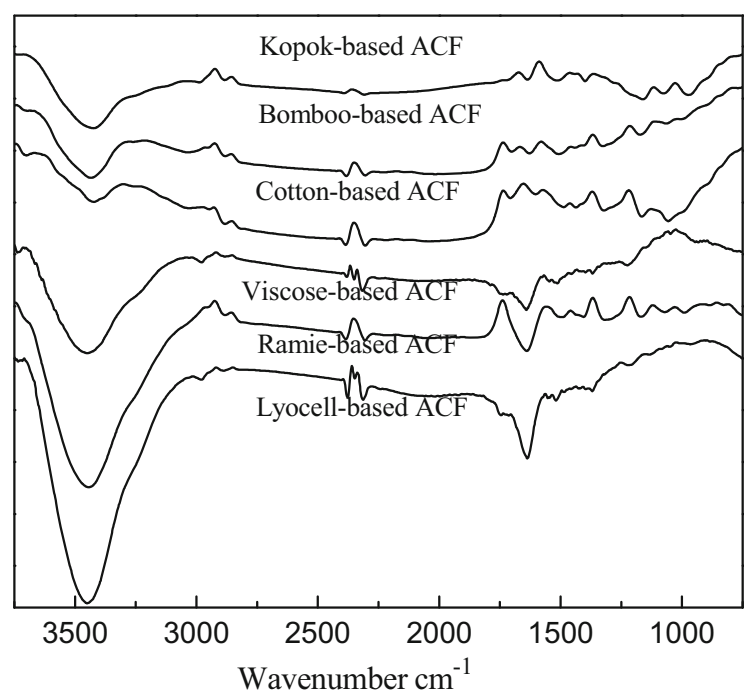

Fig. 1 Infrared transmittance Spectrum of all six cellulosic base ACFs patterns demonstrating that all have similar crystalline structure. Two broad peaks common for carbon materials appear at approximately at $23^{\circ}$ and $42^{\circ}$ corresponding to the (002) and (100) crystal planes, respectively. This similarity indicates that all cellulose-based ACFs have graphite structure with micro crystallinity. Since viscose and bamboo ACFs (002) diffraction peaks appear at a slightly higher angle than others, and it is due to the fact that preparation of cellulosic regenerated ACFs cause the carbon reduction and eventually higher organized structure.

Elemental analysis was performed to obtain the compositions of $\mathrm{C}, \mathrm{H}, \mathrm{O}$ atoms and ash of the cellulose-based ACFs. It can be seen from Table 2 that the cellulose-based ACFs used in the experiment have $\mathrm{C}, \mathrm{H}$ and $\mathrm{O}$ as its major elements and show no sulfur content. Element $\mathrm{C}$ was the most abundant constituent for the cellulose-based ACFs (above $70 \mathrm{wt} \%$ ). So the cellulose fibres are good precursor for the preparation of activated carbon fiber. A small amount of ash appears for all the cellulose-based ACF, possibly due to the raw material being immersed in the flame retardant (which is bonded with cellulose at the oxidization stage), or by nitrogen molecules of high electron binding energy forming a chemical bond on the ACF surface during high temperature activation (Zheng et al. 2014). The element ash of the lyocellbased ACF is more than that of other ACFs, mainly caused by the flame retardant in the commercial lyocell fiber. The oxygen content of the natural cellulose-based ACFs has more than that of the regenerated cellulose-based ACFs, which is probably

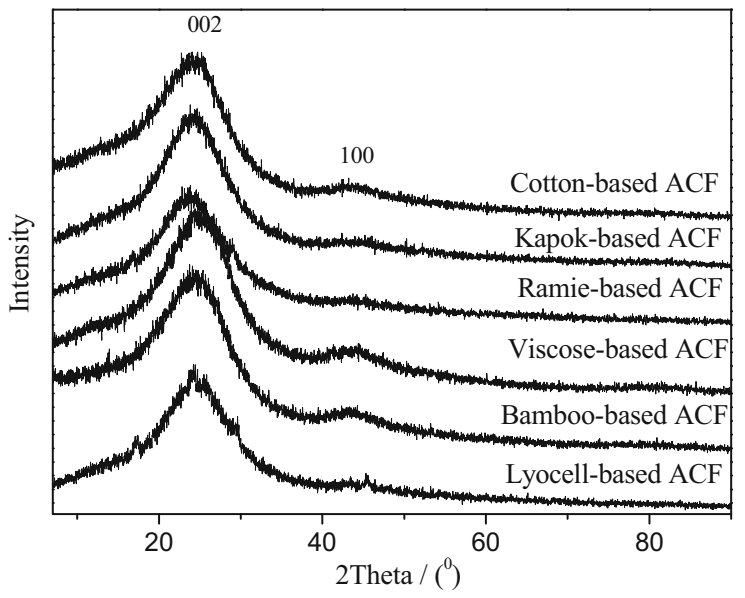

Fig. 2 X-ray diffraction of all six cellulose-based ACFs 
Table 2 Percentage of elements present in all six cellulose-based ACF

\begin{tabular}{llllll}
\hline Sample & $\mathrm{C}(\%)$ & $\mathrm{H}(\%)$ & Ash $(\%)$ & $\mathrm{S}(\%)$ & $\mathrm{O}(\%)$ \\
\hline Kapok-based ACFs & 75.35 & 0.25 & 1.15 & 0 & 23.25 \\
Bamboo-based ACFs & 76.60 & 1.47 & 2.35 & 0 & 19.58 \\
Ramie-based ACFs & 72.43 & 5.31 & 1.96 & 0 & 20.30 \\
Cotton-based ACFs & 72.86 & 3.05 & 2.44 & 0 & 21.65 \\
Lyocell-based ACFs & 72.54 & 4.55 & 5.50 & 0 & 15.41 \\
Rayon-based ACFs & 73.54 & 6.41 & 1.81 & 0 & 18.24 \\
\hline
\end{tabular}

due to the more impurity in the natural cellulose-based ACFs. Hydrogen content is more in regenerated cellulosic activated carbon fibres than natural cellulosic.

The calibration of standard curve of absorbance is first done with methylene blue, then fitting and regression equation is obtained to study the adsorption properties of ACFs. The standard curve fitting equation is $\mathrm{y}=0.09839 \mathrm{x}+0.03264\left(\mathrm{R}^{2}=0.9915\right)$. As the correlation coefficient is higher so the concentration of methylene blue solution has a good linear correlation and used further. The adsorption volume graph of the MB for the six cellulose-based ACFs is shown in Fig. 3. It is seen that as the time increase, the adsorption of $\mathrm{MB}$ for the cellulose-based ACFs increases. In these figures, the prepared cellulosebased ACFs have the different MB adsorption capacity. The highest adsorption capacity from liquid phase is found for the kapok-based ACFs, which reach adsorption saturation in $2 \mathrm{~min}$. A significant absorption of MB is observed for the bamboo-based ACFs. Compared with the kapok-based ACFs, the bamboobased ACFs need slightly more time and reach adsorption saturation after 6 min. Adsorption saturation reached by ramie ACFs in $15 \mathrm{~min}$ and by pure cotton ACFs in $30 \mathrm{~min}$. The viscose-based ACFs are much less effective adsorbents. The least effective adsorbents are the lyocell-based ACFs. In 80 min the viscose ACFs adsorption volume only tends to balance and saturated while the tencel ACFs the volume of adsorption is unlikely to change as time increases. For the cellulose-based ACFs, the order for the adsorption capacity is: kapok-based ACF > bamboo-based ACFs $>$ ramie-based ACFs $>$ cotton-based ACFs $>$ viscose-based ACFs $>$ tencel-based ACFs. We expect that the homogeneous hollow-tube-shaped ACFs produced in this study can be widely applied for the removal of pollutants from aqueous solutions.

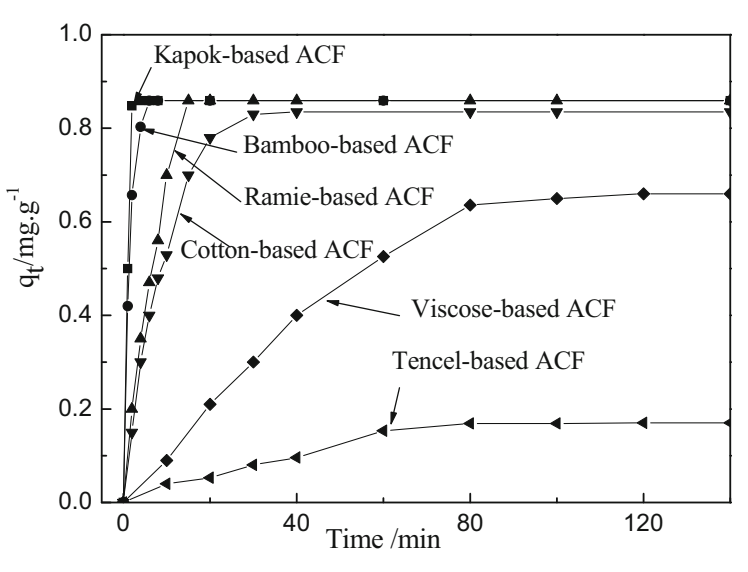

Fig. 3 Adsorption of methylene blue on ACFs derived from six cellulosic fibres

To further compare their adsorption rate, widely used models (the pseudo-first-order, pseudo-secondorder and Elovich models) were employed to fit the date. The absorption kinetics was analyzed by the absorption equations as follows:

Pseudo-first order kinetics equation: $\ln \left(\mathrm{q}_{\mathrm{e}} / \mathrm{q}_{\mathrm{t}}\right)$

$=\operatorname{lnq}_{\mathrm{e}}-\mathrm{k}_{1} \mathrm{t}$

Pseudo second order kinetics equation: $t / q_{t}$

$$
=1 /\left(\mathrm{k}_{2} \mathrm{q}_{\mathrm{e}}^{2}\right)+\mathrm{t} / \mathrm{q}_{\mathrm{e}}
$$

Elovich model: $\mathrm{q}_{\mathrm{t}}=(1 / \beta) \ln \alpha \beta+(1 / \beta) \ln \mathrm{t}$

where $\mathrm{q}_{\mathrm{t}}$ shows the amount of MB adsorbed $(\mathrm{mg} / \mathrm{g})$ at various adsorption time $\mathrm{t}(\mathrm{min}) ; \mathrm{q}_{\mathrm{e}}$ expresses the maximum adsorption capacity; $\mathrm{k}_{1}$ and $\mathrm{k}_{2}$ are the firstorder and second-order rate constants for the adsorption process respectively, $\alpha$ is initial rate of adsorption and $\beta$ is constant associated with the chemisorption and activation energy of surface. Elovich model is applicable when thas very large value (i.e. $t \gg 1 / \alpha \beta$ ) 
and isn't applicable when two separate and independent process are involved such as the initial uptake and subsequent slow process (Su et al. 2012).

The correlated parameters of six cellulose-based ACFs were calculated and summarized in Table 3. It was observed that the MB adsorption by cellulosebased ACFs follows the pseudo-second-order reaction with high correlation coefficients $\left(\mathrm{R}^{2}>0.99\right)$, and the adsorption capacity $\left(\mathrm{q}_{\mathrm{e}, \mathrm{cal}}\right)$ from the pseudo-secondorder model was much closer to the experimental data $\left(\mathrm{q}_{\mathrm{e}, \exp }\right)$, which suggested that the process controlling the rate may be a chemical sorption (Aharoni and Tompkins 1970). This result is consistent with that in literature, where the pseudo-second-order model fitted well for bamboo-based activated carbon (Wang et al. 2007; Hameed et al. 2007b). The $\mathrm{R}^{2}$ value of Elovich model is also clear evidence that controlling rate process is chemical sorption. It is also noted that the maximum adsorption capacities are significantly influenced by the cellulose matrix. Clearly, the kapok ACF possesses the highest adsorption capacity due to the hollow structure, while the adsorption capacities of the tencel ACF remains at the bottom.

The surface characteristics of cellulose-based ACFs are largely determined by the nature of the precursor fibres, which is noticeable from the SEM photographs in the Fig. 4. After carbonization and activation, all cellulose-based ACFs retain fibrous structure of the precursor fibres. It shows that the prepared kapok-based ACFs exhibit a homogeneous hollow-tube structure with an average diameter of $15 \mu \mathrm{m}$. In addition, the wall is longitudinal smooth with $1 \mu \mathrm{m}$ thickness in width on average. The kapok- based ACFs have more specific area and gap than other cellulosic ACFs, which greatly improves the MB adsorption capacity. Many striped holes are along the axes of kapok fiber on the surface, which shows the reagent (ammonium phosphate) helps to form pores originating from kapok fiber (Liu et al. 2010). The collapse of kapok-based ACFs appears and a wider porosity is obtained.

The bamboo fibres are the cellulose fibres extracted and fabricated from natural bamboo. It shows that the ACFs have uniform size. The bamboo-based ACFs are longitudinal, has more root and channels, weight distribution is not uniform, fibres are comparatively depressed and surface has countless micro concave slot. As it can be seen from the SEM photographs, the ramie-based ACFs have visible fibrils on the surface due to previously removal of hemicelluloses and lignin from middle lamella during the $\mathrm{NaOH}$ pretreatment (Aharoni and Tompkins 1970). The longitudinal cracks along the fiber are also observed. The cottonbased ACFs appear to a curly form in longitudinal and have a fibrous filament structure with cavities on its surface. Some long or short irregular and discontinuous slits can be observed. The fiber surface has many small pores. The sectional dimension of cotton-based ACFs is about $11.7 \mu \mathrm{m}$. The microstructure of viscose-based ACFs is similar to that of the bamboobased ACFs. The viscose-based ACFs are approximately cylindrical with a diameter of nearly $10 \mu \mathrm{m}$, and the fiber surface is very smooth but full of grooves. The tencel-based ACFs have very smooth structure and highly packed resulting in poor adsorption of MB.

Table 3 Adsorption kinetics of methylene blue of six cellulosic based ACFs

\begin{tabular}{|c|c|c|c|c|c|c|c|c|c|c|}
\hline \multirow[t]{2}{*}{$\begin{array}{l}\text { ACFs } \\
\text { Samples }\end{array}$} & \multirow[t]{2}{*}{$\begin{array}{l}\mathrm{q}_{\mathrm{e} 2} \\
\left(\mathrm{mg} \mathrm{g}^{-1}\right)\end{array}$} & \multicolumn{3}{|c|}{$\begin{array}{l}\text { Pseudo-First order kinetics } \\
\text { equation }\end{array}$} & \multicolumn{3}{|c|}{ Second-order kinetics equation } & \multicolumn{3}{|c|}{ Elovich equation } \\
\hline & & $\begin{array}{l}\mathrm{k}_{1} \\
\left(\min ^{-1}\right)\end{array}$ & $\mathrm{R}^{2}$ & $\begin{array}{l}\mathrm{q}_{\mathrm{e} 1} \\
\left(\mathrm{mg} \mathrm{g}^{-1}\right)\end{array}$ & $\begin{array}{l}\mathrm{k}_{2} \\
\left(\min ^{-1}\right)\end{array}$ & $\mathrm{R}^{2}$ & $\begin{array}{l}\mathrm{q}_{\mathrm{e} 1} \\
\left(\mathrm{mg} \mathrm{g}^{-1}\right)\end{array}$ & $\begin{array}{l}\mathrm{A} \\
\mathrm{g}(\mathrm{mg} \mathrm{h})^{-1}\end{array}$ & $\begin{array}{l}\beta \\
\left(\mathrm{mg} \mathrm{g}^{-1}\right)\end{array}$ & $\mathrm{R}^{2}$ \\
\hline Kapok & 0.859 & 1.61 & 0.852 & 0.125 & 0.70 & 0.9903 & 0.899 & 17.85 & 3.815 & 0.9286 \\
\hline Bamboo & 0.859 & 0.63 & 0.849 & 0.363 & 0.39 & 0.9965 & 0.869 & 15.71 & 3.273 & 0.9527 \\
\hline Ramie & 0.859 & 0.13 & 0.982 & 0.375 & 0.059 & 0.9918 & 0.854 & 2.41 & 3.300 & 0.8503 \\
\hline Cotton & 0.835 & 0.13 & 0.962 & 0.45 & 0.069 & 0.9994 & 0.853 & 206 & 3.85 & 0.8503 \\
\hline Rayon & 0.66 & 0.005 & 0.769 & 0.22 & 0.00063 & 0.9986 & 0.690 & 2.95 & 3.648 & 0.8857 \\
\hline Tencel & 0.17 & 0.007 & 0.799 & 0.06 & 0.0114 & 0.9963 & 0.208 & 7.32 & 16.12 & 0.8856 \\
\hline
\end{tabular}



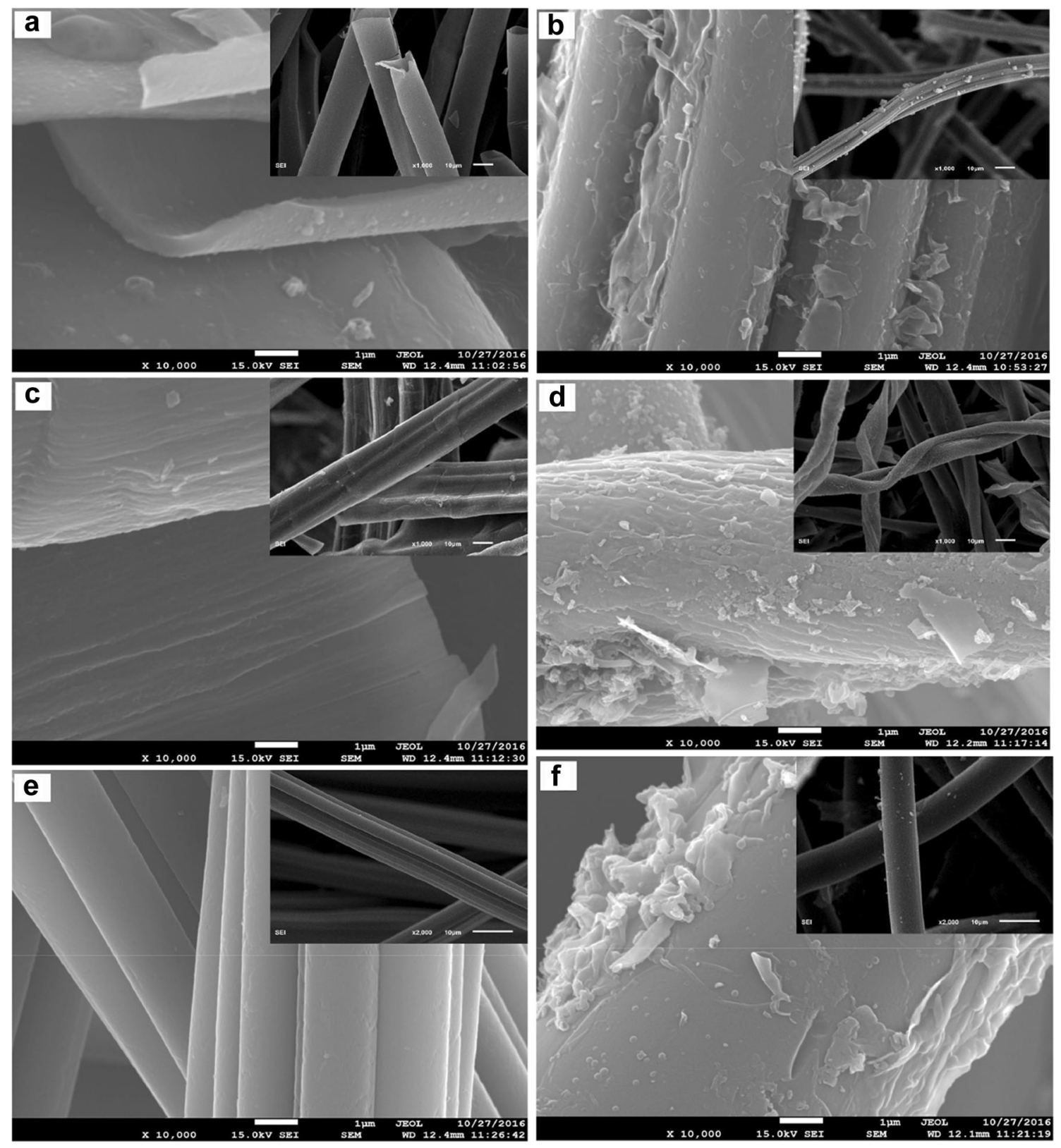

Fig. 4 The surface morphology of the six cellulose-based ACFs a Kapok, b Bamboo, $\mathbf{c}$ Ramie, $\mathbf{d}$ Cotton, e Viscose, f Tencel

The $\mathrm{N}_{2}$ adsorption-desorption isotherms of the cellulose-based ACF are performed to obtain further information about their porous structure. The isotherms of $\mathrm{N}_{2}$ adsorption-desorption at $77 \mathrm{~K}$ of the cellulose-based ACFs are shown in Fig. 5. The calculated surface area and pore structure characteristics of the cellulose-based ACFs are listed in Table 3. For the cellulose-based-based ACFs, the more obvious hysteresis loop can be observed in Fig. 5 at relative pressure $\left(\mathrm{P} / \mathrm{P}_{0}\right)$ of $0.4-0.8$, suggesting that the isotherm is type IV (Wang et al. 2007). It proceeds via multilayer adsorption followed by capillary condensation, indicating the coexistence of micropores and a considerable amount of mesopores $(2-50 \mathrm{~nm})$. As the condensation of capillaries occurs in the adsorption process of mesopores, desorption process must occur at a low partial pressure, so the hysteresis loop can occur. The onset of the hysteresis loop (where 


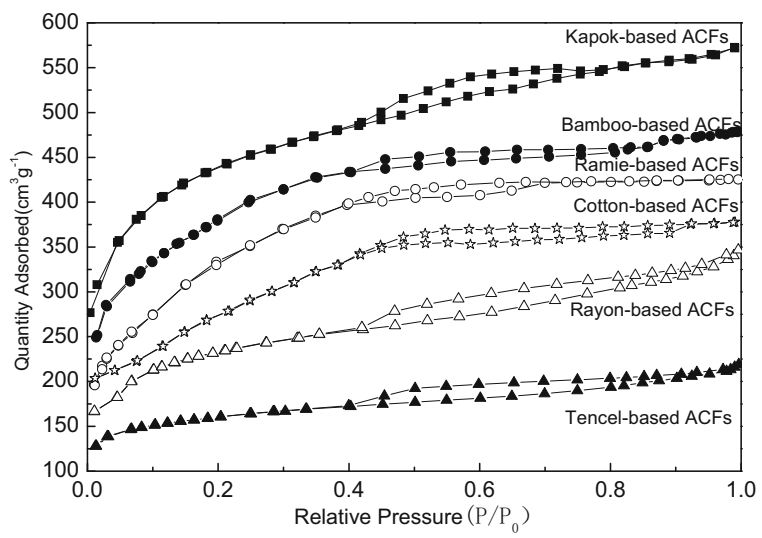

Fig. $5 \mathrm{~N}_{2}$ adsorption-desorption isotherms of all six cellulosebased ACFs

$\mathrm{p} / \mathrm{p}_{0}$ is about 0.4$)$ indicates the beginning of the capillary condensation in the pores (Mayagoitia 1991).

From the data in the Table 4, it can be seen that the precursors have some influence on the specific surface area and pore structure of the ACFs. The pore structure of cellulose-based ACFs is basically mesoporous with the average pore diameters of 2.57-3.52 nm. For the kapok-based ACF, the $\mathrm{S}_{\mathrm{BET}}$ and $\mathrm{V}_{\text {tot }}$ have maximum values of $1510.0 \mathrm{~m}^{2} / \mathrm{g}$ and $0.875 \mathrm{~cm}^{3} / \mathrm{g}$, respectively, which is consistent with the best absorption of MB. The specific surface area of the kapok-based ACF is almost two and a half times that of the tencel ACF $\left(590.6 \mathrm{~m}^{2} / \mathrm{g}\right)$. The bamboo-based ACF also has higher specific surface area $\left(1455.6 \mathrm{~m}^{2} / \mathrm{g}\right)$ and micro-pore volume than all other cellulose-based ACFs. The bamboo-based ACF exhibits surface groove and fibrillation, which influences the absorption of MB. The specific surface area of the cotton-based ACF reaches $1020.0 \mathrm{~m}^{2} / \mathrm{g}$, that is almost twice that of the tencel-based ACF $\left(590.6 \mathrm{~m}^{2} / \mathrm{g}\right)$. The precursors of regenerated cellulose fibres including bamboo, rayon and tencel are fabricated by wet-spinning and the skincore structure is formed at the cross section at the wetspinning process. The skin-core structure hinders the chemical activation and the pre-oxidation of the regenerated cellulosic precursors, which affects on the pore structure of ACFs. Moreover, the skin-core structure remains at the regenerated cellulose-based ACFs. Except the bamboo-based ACFs, the regenerated cellulose-based ACFs have the lower specific surface and absorption property of MB. The specific surface area of the prepared rayon-based ACF is $980.2 \mathrm{~m}^{2} / \mathrm{g}$, with the mean diameter of $2.31 \mathrm{~nm}$. The tencel-based ACF has the minimum specific surface area and the worst absorption of MB. It was possibly because that thicker skin in the skin-core structure and smooth surface probably formed at wet-spinning process. The result from this can be drawn that the

Table 4 Specific surface area and pore structure of six cellulose-based ACFs

\begin{tabular}{|c|c|c|c|c|c|c|}
\hline Sample & $\begin{array}{l}\text { Specific Surface } \\
\text { area }\left(\mathrm{m}^{2} / \mathrm{g}\right)\end{array}$ & $\begin{array}{l}\text { Micro-pore specific } \\
\text { surface area }\left(\mathrm{m}^{2} / \mathrm{g}\right)\end{array}$ & $\begin{array}{l}\text { Total hole } \\
\text { product }\left(\mathrm{cm}^{3} /\right. \\
\text { g) }\end{array}$ & $\begin{array}{l}\text { Micro-pore } \\
\text { volume }\left(\mathrm{cm}^{3} / \mathrm{g}\right)\end{array}$ & $\begin{array}{l}\text { Micro-pore volume } \\
\text { proportion }(\%)\end{array}$ & $\begin{array}{l}\text { The average } \\
\text { pore size }(\mathrm{nm})\end{array}$ \\
\hline $\begin{array}{r}\text { Kapok- } \\
\text { based } \\
\text { ACFs }\end{array}$ & 1510.0 & 1322.0 & 0.875 & 0.786 & 89.83 & 1.91 \\
\hline $\begin{array}{l}\text { Ramie- } \\
\text { based } \\
\text { ACFs }\end{array}$ & 1286.4 & 1044.0 & 0.620 & 0.410 & 66.10 & 2.05 \\
\hline $\begin{array}{r}\text { Cotton- } \\
\text { based } \\
\text { ACFs }\end{array}$ & 1020.0 & 700.6 & 0.573 & 0.288 & 50.30 & 2.19 \\
\hline $\begin{array}{c}\text { Bamboo- } \\
\text { based } \\
\text { ACFs }\end{array}$ & 1455.6 & 1228.01 & 0.730 & 0.539 & 73.90 & 1.99 \\
\hline $\begin{array}{r}\text { Rayon- } \\
\text { based } \\
\text { ACFs }\end{array}$ & 980.2 & 540.3 & 0.520 & 0.200 & 38.46 & 2.31 \\
\hline $\begin{array}{c}\text { Tencel- } \\
\text { based } \\
\text { ACFs }\end{array}$ & 590.6 & 220.4 & 0.350 & 0.080 & 22.86 & 2.98 \\
\hline
\end{tabular}


kapok and bamboo-based ACFs has the largest adsorption, more suitable for absorbency. While rayon and tencel-based ACF adsorption capacity are relatively small and not suitable for absorbency and explain the different trends of the adsorption of methylene blue by different ACFs.

\section{Conclusion}

Three natural cellulosic fibres (kapok, ramie and cotton) and three regenerated cellulosic fibres (bamboo, viscose and tencel) are used to make ACFs by chemical activation method. The characterization of the ACFs is done by the SEM, FTIR spectroscopy, and XRD. Internal structure and adsorption properties of the all six kinds of ACFs are also studied. The six cellulose-based ACFs have almost similar FTIR spectra, suggesting similarity in their chemical structure but differences appear in peak intensities at less than $1500 \mathrm{~cm}^{-1}$ in spectra for the three natural cellulose-based ACFs, which may be attributed to more impurities and ash in the three natural cellulosic ACFs. X-ray structural analysis for all cellulose-based ACFs shows similar diffraction patterns, which demonstrates that all the ACFs have graphite micro crystallinity. Viscose and bamboo based ACFs diffraction peaks appears at a slightly higher angle than others and it is due to the fact that preparation of cellulosic regenerated ACFs cause the carbon reduction and eventually high surface defect. The cellulosic ACFs adsorption is second order kinetics and mainly is single molecular adsorption. The surface characteristics of cellulosic based ACFs were studied using SEM, specific surface area, and pore structure analysis. They revealed that the dye adsorption depends mainly on the surface morphology composed of hallow and cracked surface structures, micro-pore structures and pore surface area. Thus, more porous ACF have greater specific surface areas resulting in better adsorption. The prepared activated carbon fibres by chemical activation have a predominantly microporous structure and a large surface area.

Pseudo-second-order kinetic model have better correlation of the adsorption kinetics data than firstorder kinetic model and the adsorption-controlling rate process is chemical sorption. The adsorption capacity of the cellulose-based ACFs is the descending order of kapok, bamboo, ramie, cotton, viscose, and lyocell. The prepared Kapok-ACFs are best and have a homogeneous hollow tube shape with an average diameter of $15 \mu \mathrm{m}$, a large pore volume and a high surface area.

Acknowledgments The financial support from the National Nature Science Fund of China (51303139) and the Scientific Research Foundation of Hubei Provincial Education Department (No: Q20121710) is greatly appreciated.

\section{References}

Aber S, Khataee A, Sheydaei M (2009) Optimization of activated carbon fiber preparation from Kenaf using $\mathrm{K}_{2} \mathrm{HPO}_{4}$ as chemical activator for adsorption of phenolic compound. Bioresour Technol 100:6586-6591

Aharoni C, Tompkins EC (1970) Kinetics of adsorption and desorption and the Elovich equation. Adv Catal 21:1-49

AlcaAiz-Monge J, Linares-Solano A, Rand B (2002) Mechanism of adsorption of water in carbon micropores as revealed by a study of activated carbon fibres. J Phys Chem B 106:3209-3216

Altenor S, Carene B, Emmanuel E, Lambert J, Ehrhardt JJ, Gaspard S (2009) Adsorption studies of methylene blue and phenol onto vetiver roots activated carbon prepared by chemical activation. J Hazard Mater 165:1029-1039

Avelar FF, Bianchi ML, Goncalves M, Mota JEG (2009) The use of Pissava fibres (Attalea funifera) in the preparation of activated carbon. Biosour Technol 101:639-4645

Dąbrowski A, Podkościelny P, Hubicki Z, Barczak M (2005) Adsorption of phenolic compounds by activated carbon-a critical review. Chemosphere 58:1049-1070

Dastgheib SA, Karanfil T, Cheng W (2004) Tailoring activated carbons for enhanced removal of natural organic matter from natural waters. Carbon N Y 42:547-557

Du X, Zhao W, Wang Y, Wang C, Chen M, Qi T, Hua C, Ma M (2013) Preparation of activated carbon hollow fibres from ramie at low temperature for electric double-layer capacitor applications. Bioresour Technol 149:31-37

El Qada EN, Allen SJ, Walker GM (2006) Adsorption of methylene blue onto activated carbon produced from steam activated bituminous coal: a study of equilibrium adsorption isotherm. Chem Eng J 124:103-110

Gupta VK, Suhas (2009) Application of low-cost adsorbents for dye removal-a review. J Environ Manag 90:2313-2342

Hameed BH, Ahmad AL, Latiff KNA (2007a) Adsorption of basic dye (methylene blue) onto activated carbon prepared from rattan sawdust. Dyes Pigments 75:143-149

Hameed BH, Din ATM, Ahmad AL (2007b) Adsorption of methylene blue onto bamboo-based activated carbon: kinetics and equilibrium studies. J Hazard Mater 141:819-825

Kumagai S, Ishizawa H, Toida Y (2010) Influence of solvent type on dibenzothiophene adsorption onto activated carbon fiber and granular coconut-shell activated carbon. Fuel 89:365-371 
Lee T, Ooi CH, Othman R, Yeoh FY (2009) Activated carbon fiber- the hybrib of carbon fiber and activated carbon. Adv Mater Sci 36:118-136

Liu QS, Zheng T, Li N, Wang P, Abulikemu G (2010) Modification of bamboo-based activated carbon using microwave radiation and its effects on adsorption of methylene blue. Appl Surf Sci 256:3309-3315

Maciá-Agulló JA, Moore BC, Cazorla-Amorós D, LinaresSolano A (2004) Activation of coal tar pitch carbon fibres: physical activation versus chemical activation. Carbon N Y 42:1361-1364

Mayagoitia V (1991) The five type of porous structures and their hyteresis loops. Stud Surf SciCatal 62:51-60

Mochida I, Korai Y, Shirahama M, Kawano S (2000) Removal of SOx and NOx over activated carbon fibres. Carbon 38:227-239

Naindi M, Okada K, Dutta A, Bhaumik A, Maruyama J, Derks D, Uyama $\mathrm{H}$ (2012) Unprecedented $\mathrm{CO}_{2}$ uptake over highly porous $\mathrm{N}$-doped activated carbon monoliths prepared by physical activation. Chem Commun 48:10283-10285

Okada K, Yamamoto N, Kameshima Y, Yasumori A (2003) Adsorption properties of activated carbon from waste newspaper prepared by chemical and physical activation. J Colloid Interface Sci 262:194-199

Pelekani C, Snoeyink VL (1999) Competitive adsorption in natural water: role of activated carbon pore size. Water Res 33:1209-1219

Phan NH, Rio S, Faur C, Le Coq L, Le Cloirec P, Nguyen TH (2006) Production of fibrous activated carbons from natural cellulose (jute, coconut) fibres for water treatment applications. Carbon N Y 44:2569-2577

Rosas LM, Bedia J, Rodríguez-Mirasol J, Cordero T (2009) HEMP-derived activated carbon fibres by chemical activation with phosphoric acid. Fuel 88:19-26

Shrestha S, Son G, Lee SH, Lee TG (2013) Isotherm and thermodynamic studies of $\mathrm{Zn}$ (II) adsorption on lignite and coconut shell-based activated carbon fiber. Chemosphere 92:1053-1061

Singh KP, Mohan D, Sinha S, Tondon GS, Gosh D (2003) Color removal from wastewater using low-cost activated carbon derived from agricultural waste material. Ind Eng Chem Res 42:1965-1976

Su CI, Zeng ZL, Peng CC, Lu CH (2012) Effect of temperature and activators on the characteristics of activated carbon fibres prepared from viscose-rayon knitted fabrics. Fibres Polym 13:21-27

Subramanian V, Luo C, Stephan AM, Nahm KS, Thomas S, Wei B (2007) Supercapacitors from activated carbon derived from banana fibres. J Phys Chem C 111:7527-7531

Suhas, Carrott PJM, Ribeiro Carrott MML (2007) Lignin-from natural adsorbent to activated carbon: a review. Bioresour Technol 98:2301-2312

Vargas AMM, Cazetta AL, Kunita MH, Silva TL, Almeida VC (2011) Adsorption of methylene blue on activated carbon produced from flamboyant pods (Delonix regia): study of adsorption isotherms and kinetic models. Chem Eng $\mathrm{J}$ 168:722-730

Wang YQ, Zhou MH, Rong D, Han B (2007) Preparation and characterization of a novel activated carbon fiber based on kapok. In: Proceedings of International Conference on advanced fibres and polymer material, pp 571-574

Williams PT, Reed AR (2006) Development of activated carbon pore structure via physical and chemical activation of biomass fibre waste. Biomass Bioenerg 30:144-152

Zhang S, Shao T, Kose HS, Tanju K (2010) Adsorption of aromatic compounds by carbonaceous adsorbents: a comparative study on granular activated carbon, activated carbon fiber, and carbon nanotubes. Environ Sci Technol 44:6377-6383

Zheng JY, Zhao QL, Ye ZF (2014) Preparation and characterization of activated carbon fiber (ACF) from cotton woven waste. Appl Surf Sci 299:86-91 